\title{
Birthweight and preterm birth in relation to indicators of childhood asthma
}

\author{
KITAW Demissie MD PhD, PieRRE ERNSt MD MSC, LAWRENCE JOSEPH PhD, \\ MARGARET R BECKLAKE MD \\ Respiratory Epidemiology Unit, McGill University, Montreal, Quebec
}

K DEMISSIE, P ERNST, L JOSEPH, MR BECKLAKE. Birthweight and preterm birth in relation to indicators of childhood asthma. Can Respir J 1997;4(2):91-97.

BACKGROUND: Early life events may have long term consequences on respiratory health including the risk of developing asthma.

OBJECTIVE: To examine the independent roles of birthweight and preterm birth on childhood asthma after accounting for socioeconomic status.

METHODS: A total of 989 elementary school children performed spirometry before and after a free-running exercise challenge. A subsample of 327 children underwent methacholine bronchoprovocation and allergy skin prick tests to common inhaled aeroallergens. Information on birthweight and preterm birth was obtained by parental interview. Socioeconomic status was established using parental occupation.

RESULTS: After adjusting for the effects of important confounding variables, birthweight was positively associated with forced vital capacity (FVC) and forced expiratory volume in $1 \mathrm{~s}\left(\mathrm{FEV}_{1}\right)$; FVC increased $4.5 \%$ per $\mathrm{kg}(95 \% \mathrm{CI}$ 1.7 to 7.4 ) and $\mathrm{FEV}_{1} 4.4 \%$ per $\mathrm{kg}$ (95\% CI 1.8 to 7.2 ). Birthweight was not related to exercise-induced bronchospasm or an asthma diagnosis, but airway responsiveness to methacholine increased as birthweight decreased $(\mathrm{P}=0.01)$. Preterm birth independent of birthweight was associated with a lower FEV $1 / \mathrm{FVC}(-1.7 \% ; 95 \%$ CI -2.8 to -0.5 ).

CONCLUSIONS: Birthweight appears to be related to lung size and methacholine responsiveness while preterm birth appears to diminish airway size.
Key Words: Bronchial hyper-responsiveness, Early life events, Lung function

\section{Poids de naissance et prématurité en relation avec des indicateurs de l'asthme chez l'enfant}

HISTORIQUE : Certains événements qui surviennent dès la naissance peuvent avoir des conséquences durables y compris le risque du développement de l'asthme.

OBJECTIF : Examiner les rôles indépendants du poids de naissance et de la naissance prématurée sur l'asthme de l'enfance après avoir pris en considération le statut socioéconomique.

MÉTHODES : On a pratiqué des tests spirométriques chez 989 enfants de l'école primaire avant et après une compétition de course libre. Un sous-échantillon de 327 enfants ont subi une épreuve de provocation bronchique à la méthacoline et des tests cutanés d'allergies à des aéroallergènes inhalés courants. Les données sur le poids de naissance et la prématurité ont été recueillies auprès des parents. On a défini le statut socioéconomique en fonction du type d'emploi des parents.

RÉSULTATS : Après une correction en fonction des effets de variables importantes se confondant, le poids de naissance était associé de manière positive à la capacité vitale forcée $(\mathrm{CVF})$ et au VEMS (volume expiratoire maximal/seconde) ; la CVF augmentait de 4,5\% par kg (IC $95 \%$ 1,7 à 7,4) et le VEMS de 4,4\% par $\mathrm{kg}$ (IC $95 \%$ 1,8 à 7,2). Le poids de naissance n'était pas associé au bronchospasme induit par l'exercice ou à un diagnostic d'asthme, mais la réponse des voies aériennes à la méthacoline augmentait lorsque le poids de naissance diminuait $(\mathrm{P}=0,01)$. $\mathrm{La}$ naissance prématurée indépendamment du poids de naissance était associée à une diminution du rapport VEMS/CVF $(-1,7 \%$; IC $95 \%-2,8$ à $-0,5)$.

CONCLUSIONS : Le poids de naissance semble être associé à la taille des poumons et à une réponse à la méthacholine alors qu'une naissance prématurée semble diminuer le calibre des voies aériennes.

Correspondence and reprints: Dr Pierre Ernst, Respiratory Epidemiology Unit, McGill University, 1110 Pine Avenue West, Montreal, Quebec H3A 1A3. Telephone 514-398-6974, fax 514-398-8981, e-mail Ernst@meakins.lan.mcgill.ca 
P rolonged follow-up of birth cohorts from Britain has strongly suggested that the factors that affect the early development of the lungs and airways have important repercussions throughout life $(1,2)$. Infants have differences in measures of airway and lung size that predate and appear to predict subsequent wheezing illnesses (3) related to viral infection.

Both preterm birth and birthweight have been associated with an excess of childhood respiratory morbidity in the form of symptoms (4-6), reduced lung function (5,7-11), airway hyper-responsiveness (12) and diagnosed asthma $(5,6,11,13)$, but the results of studies have not always been consistent. Low birthweight and preterm birth are more common among disadvantaged groups (14), among whom crowding and lower respiratory tract illness are more frequent; also, poor environmental conditions associated with asthma, eg, parental smoking, may be more likely to prevail (15). Most studies reported did not control for socioeconomic status (SES) or used imprecise methods of assessing social class. Furthermore, only one study has been able to separate the effect of preterm birth without associated neonatal respiratory distress syndrome from that of low birthweight (5).

During a study of the determinants of respiratory health in Montreal elementary school children, we examined the independent effects of birthweight and preterm birth on indicators of childhood asthma after controlling for SES and other important confounding variables.

\section{SUBJECTS AND METHODS}

The study was approved by the Ethics Committee of the Department of Epidemiology and Biostatistics, McGill University, Montreal, Quebec.

\section{Cross-sectional survey in the schools}

Study population: Eighteen schools on the island of Montreal, Quebec, were selected to represent a broad range of socioeconomic status based on neighbourhood average house values. One class from each school of grades one (ages five to seven years), three (ages eight and nine years) and five (ages 10 to 13 years) was selected. Study procedures were briefly described to each class, and each child was provided with an introductory letter, a short questionnaire about the child's health and home environment, and a letter of consent to be completed by a parent.

Of the 1274 children selected, the parents of $130(10.2 \%)$ refused participation while a further $75(5.9 \%)$ children did not return the questionnaire and consent form. There were no differences in the age, sex or race of the child between participants and nonparticipants. Among families who refused permission for their child to participate in testing, but who did return the short questionnaire, mothers were less likely to be currently smoking ( $18.8 \%$ versus $37.9 \%$ ) and fathers were less likely to have a history of asthma (3.9\% versus $17.2 \%$ ). No meaningful differences were seen in respiratory symptoms, type of heating and cooking fuel used and the presence of pets.

Lung function: In the school gymnasium, each subject's age, sex, height and weight were recorded, and the children were asked whether they had experienced a respiratory tract infection within the past week. Enquiries was made concerning current smoking among the grade 5 children. Spirometry was carried out sitting with nose clips, using two Collins $10 \mathrm{~L}$ water-sealed spirometers (Warren E Collins, Maryland) according to current American Thoracic Society (ATS) guidelines (16), and the best forced expiratory volume in $1 \mathrm{~s}$ $\left(\mathrm{FEV}_{1}\right)$ from any flow-volume curve, both at baseline and after exercise, was used for analysis (17).

After 5 mins rest, heart rate was measured using a digital plethysmograph (Heart Rate Inc, California). Children were then asked to run around the gymnasium for 6 mins at a pace judged sufficient to attain $90 \%$ or more of their predicted maximal heart rate (18); heart rate was measured again immediately after completion of exercise. Five and 10 mins after completion of exercise, spirometry was repeated on the same spirometer. Subjects did not take part in the exercise test if they were excused from gym class or if their $\mathrm{FEV}_{1}$ was below $70 \%$ predicted. Temperature and humidity of the gymnasium were recorded at the time of the test. No specific instructions were given concerning the use of medications, including those for asthma. The exercise test was completed successfully in 989 children. Only $11(1.1 \%)$ children had used an inhaled beta-agonist and one $(0.1 \%)$ used theophylline in the days preceding the test. No other use of asthma medication was reported.

\section{Subsample selected for study at home}

Study subjects: A subsample of children was chosen for detailed investigation of risk factors for airway hyper-responsiveness. Children whose parents responded "yes" to the question: "Has a physician ever diagnosed asthma in your child?" and those whose FEV1 fell by $10 \%$ or greater after exercise were first selected. For each of these children, the next child on the alphabetical class list of the same sex was chosen. If the parents of the child with asthma or exercise-induced bronchospasm (EIB) refused further participation, both this child and the one chosen for comparison were not studied further; if a child chosen for comparison, that is without asthma or EIB, refused, the next appropriate child on the class list was selected. For 38 children with a history of asthma or EIB, a comparison subject of the same sex in the same class could not be obtained because of the high refusal rates in certain classes.

Respiratory questionnaires: A questionnaire regarding respiratory symptoms, medical history of the child, exposure to second-hand smoke and housing conditions, including the current presence of pets (dogs, cats, birds, hamsters, mice, guinea pigs) in the home, was administered to one of the parents by a trained interviewer (19). The following questions were asked about preterm birth and birthweight: "Was the child born prematurely? If yes, how many weeks was the child born premature?" (preterm birth); "When the child was born, was he/she kept in hospital after the mother went home?" (neonatal intervention); and "How much did this child weigh at birth? xx lbs or xx kg" (birthweight). Symp- 
toms and diagnoses were defined as follows: "Does the child's chest ever sound wheezy or whistling?" (ever wheeze) and "If yes, does the child get this on most days or nights?" (wheeze most days); "Has the child had wheezing or whistling in the chest, at any time, in the last 12 months?" (current wheeze); "Has the child ever been diagnosed to have asthma?" (history of asthma); "How many asthmatic attacks has the child had in the last 12 months?" (current asthma); "Does the child usually cough?" (usual cough); "Does the child usually cough and bring up mucus?" (cough with mucus); "Do colds usually go to the child's chest?" (usual colds); "Has the child been coughing at night or on getting up in the morning during the past month?" (night cough); "Does the child's natural father suffer from asthma?" and "Does the child's natural mother suffer from asthma?" (asthma in a parent).

Assessment of socioeconomic status: Parents' recent occupation was used to identify the corresponding codes of the Standard Occupational Classification (20). These codes were then converted into SES scores for the child, based on income and education level for each occupation (the highest score from either parent was retained for analysis) from the tables developed by Blishen and colleagues (21). Spearman's rank correlations between the SES score assessed using the most recent and the previous three jobs were, respectively: $r_{S}=0.86$, $r_{S}=0.84$ and $r_{s}=0.62$ for the mothers' jobs and $r_{s}=0.87, r_{S}=0.84$ and $r_{s}=0.81$, for fathers' jobs.

Methacholine bronchoprovocation test: The methacholine bronchoprovocation test was carried out at home in the evening. Children were asked not to use beta-2-agonists for $6 \mathrm{~h}$ before the test. Baseline spirometry was performed on each subject before the methacholine challenge using a Vitalograph pneumotachograph spirometer (Vitalograph SA, Missouri) with a nose clip applied. Each child had as many as eight trials, continuing until three curves satisfying the ATS acceptability and reproducibility criteria were obtained. All children with an $\mathrm{FEV}_{1}$ greater than $75 \%$ of their forced vital capacity underwent a methacholine challenge test using the method of Yan et al (22), differing only in the use of methacholine instead of histamine. A long protocol with nine incremental doses was followed in children with EIB or a history of asthma, with six incremental doses given to the other children. De Vilbiss 40 glass hand-held nebulizers (De Vilbiss Co, Pennsylvania) were used for administration. The output of these nebulizers was obtained through a series of measurements of weight before and after activations. The test began with three inhalations of $0.9 \%$ saline, with $\mathrm{FEV}_{1}$ measured 1 min after. Provided that the $\mathrm{FEV}_{1}$ did not fall by more than $10 \%$ of the baseline value, methacholine solutions were administered according to the following cumulative doses in micromoles: 0.030, 0.060, 0.124, 0.244, 0.499, 0.996, 1.990, 3.913 and 7.80 for the long protocol and 0.030, 0.094, 0.477, $1.967,3.89$ and 7.78 for the short protocol.

At each dose level, subjects performed inspiratory capacity inhalation with a $5 \mathrm{~s}$ breath-hold while seated and wearing nose clips. A forced expiratory manoeuvre was performed, as described above, $60 \mathrm{~s}$ after each dose. The challenge was stopped when the $\mathrm{FEV}_{1}$ had fallen by $20 \%$ or more or the final dose had been reached. Of the 332 children chosen for detailed investigation at home (children with EIB or asthma and children without these conditions), the $\mathrm{FEV}_{1}$ of four $(1.2 \%)$ children was $75 \%$ or less of their predicted value and as a result the methacholine bronchoprovocation test was not performed. The methacholine bronchoprovocation test was completed successfully in 310 children.

Allergen skin prick testing: During the home visit, a drug history was taken to ensure that the child was not using any preparation that might interfere with a response. Solutions for testing comprised histamine $(1 \mathrm{mg} / \mathrm{mL})$, normal saline, Dermatophagoides pteronyssinus, Dermatophagoides farinae, mixed grass pollens, tree pollens, ragweed, mixed moulds, Aspergillus species, cat epithelium and cockroach. The mixed moulds comprised Alternaria tenuis, Aspergillus fumigatus, Aspergillus niger, Aspergills oryzae, Aspergillus terreus, Hormodendrum hordei, Penicillium chrysoganum, Penicillium digitatum, Penicillium expansum and Penicillium notatum. Solutions for testing were obtained from Omega. Needles (26 gauge) were used to break the skin. The resultant wheal diameters were measured at right angles using Vernier calipers (Searle, West Germany) at 10 and 15 mins. A wheal at least $3 \mathrm{~mm}$ in either direction (the maximum whichever time was noted) was taken as a positive response if the normal saline control showed no reaction (less than 1 $\mathrm{mm}$ ); otherwise, the size of the reaction was subtracted from the reaction of each allergen. If there was no positive response to histamine, skin testing was regarded as invalid. A wheal size of $3 \mathrm{~mm}$ or greater was taken to indicate a positive allergic reaction to the specific antigen $(23,24)$. Valid allergy skin test results were obtained for 309 children.

\section{STATISTICAL METHODS}

The outcome variables in this analysis were lung function (forced vital capacity [FVC], FEV 1 and $\mathrm{FEV}_{1} / \mathrm{FVC}$ ), EIB, a history of asthma, airway responsiveness to methacholine, allergy skin test positivity and EIB or a history of asthma combined. The explanatory variables were birthweight and preterm birth.

Respiratory symptoms, EIB, a history of asthma, allergy skin test positivity and EIB or a history of asthma combined, in relation to the independent variables were analyzed by unconditional (including all subjects studied) and conditional (including only children with markers of asthma in whom a comparison child from the same class participated) multiple logistic regression (25). For each of these outcomes and independent variables, a separate regression model was constructed. Statistical significance of regression coefficients were determined by the $\chi^{2}$ approximation to the likelihood ratio statistic. Because the results obtained from the conditional and unconditional logistic regression models were similar and, in an attempt to include as many subjects as possible, the results of the unconditional multiple logistic regression models are presented.

For the methacholine bronchoprovocation test, the dose response data of each child were summarized by the method 


\section{TABLE 1}

Descriptive characteristics of responders to initial questionnaire in the cross-sectional survey at schools

\begin{tabular}{lcc}
\hline & Number & Percentage \\
\hline Boys & 553 & 49.9 \\
Symptoms/diagnosis ( $\mathrm{n}=1101)$ & & \\
$\quad$ Usual cough & 113 & 10.3 \\
$\quad$ Night cough & 112 & 10.2 \\
$\quad$ Ever wheeze & 117 & 10.6 \\
$\quad$ History of asthma & 133 & 12.1 \\
$\quad$ Current asthma & 51 & 4.6 \\
$\quad$ Asthma treatment & 50 & 4.5 \\
Parent currently smoking ( $\mathrm{n}=1111)$ & & \\
$\quad$ Neither* & 538 & 48.4 \\
$\quad$ Mother only & 203 & 18.3 \\
$\quad$ Father only* & 180 & 16.2 \\
$\quad$ Both & 190 & 17.1 \\
Child shares bedroom $(\mathrm{n}=1109)$ & 487 & 43.9 \\
Child attended day care $(\mathrm{n}=1102)$ & 373 & 33.9 \\
Pets in home, current $(\mathrm{n}=1109)$ & & \\
$\quad$ Any & 503 & 45.4 \\
$\quad$ Cats & 209 & 18.9 \\
Exercise-induced bronchospasm & 189 & 19.1 \\
( $\mathrm{n}=989)^{\dagger}$ & & \\
\hline
\end{tabular}

${ }^{*} 318(28.6 \%)$ are monoparental; ${ }^{\dagger}$ Fall in forced expiratory volume in 1 s $10 \%$ or greater

of O'Connor et al (26). The dose response slope (DRS) was ranked because of the nonnormal distribution of DRS, which persisted despite various transformations. The ranks were used as an outcome variable for subsequent multivariate analysis and approximate normality was obtained in their residuals.

$\mathrm{FVC}, \mathrm{FEV}_{1}$ and $\mathrm{FEV}_{1} / \mathrm{FVC}$ were transformed into a natural logarithmic scale (LN) and were regressed on LN (standing height), LN (age) and LN (body mass index), sex and race. Constant variance and normality were obtained in the residuals. The relationship of these residuals to birthweight and preterm birth was then examined using least squares regression. To express the results as percentage change, the antilogarithm of each regression coefficient was computed and multiplied by 100 . Thus, associations between outcomes and exposure measures were expressed as change from $100 \%$ in the ratio of observed to expected (27).

Statistical significance was defined as a two-tailed $\mathrm{P}<0.05$. Statistical analysis was carried out using SAS (SAS Institute Inc, North Carolina) and EGRET (SERC, Washington) statistical softwares.

\section{RESULTS}

Table 1 provides descriptive characteristics of the participants in the component of the study carried out in the schools. The prevalence of occasional and persistent wheezing is quite low compared with published results in similar populations; this is not the case for the prevalence of asthma. This is likely due to the unsatisfactory translation of the term wheezing into French and has been described previously in studies carried out in Quebec (28).

Of the 269 children with either EIB or a history of asthma, $187(70 \%)$ were visited at home. Of the 231 children chosen for comparison, 145 (63\%) were visited. Reasons for nonparticipation among the cases and controls, respectively, were refusals (66 [25\%] and 49 [21\%]), not reached (9 [3\%] and $26[11 \%])$, excluded because of language problem (2 [0.7\%] and $2[0.9 \%])$, wrong telephone number $(2[0.7 \%]$ and 2 $[0.9 \%])$, no telephone number (1 [0.4] and $2[0.9 \%])$ logistical reasons $(1[0.4 \%]$ and 2 [0.9\%]), and other reasons (1 $[0.4 \%]$ and $2[0.9 \%])$. Among children with EIB or a history of asthma (Table 2), nonparticipants were more likely to be Caucasian, have mothers or fathers who smoke or mothers who had smoked during pregnancy. Among the comparison group, differences between participants and nonparticipants were less pronounced, though mostly similar to those with EIB or a history of asthma.

Lung function: The mean birthweight of the 300 children (90.4\%) whose parents provided this information was $3.2 \mathrm{~kg}$ $(\mathrm{SD}=0.6)$. Only two children had a birthweight of $1.5 \mathrm{~kg}$ or less, while $34(11.3 \%)$ children had a birthweight of $2.5 \mathrm{~kg}$ or less. Birthweight variables created using cut-off values of 1.5 and $2.5 \mathrm{~kg}$ could not be used in the analysis because of the small numbers involved. Birthweight was therefore considered as a continuous variable.

Separate regression models were constructed for the outcomes FVC, FEV 1 and $\mathrm{FEV}_{1} / \mathrm{FVC}$. When examining the effect of birthweight alone, the estimated increases in FVC, $\mathrm{FEV}_{1}$ and $\mathrm{FEV}_{1} / \mathrm{FVC}$ associated with an increase in birthweight of $1 \mathrm{~kg}$ were $2.8 \%$ (95\% CI 0.5 to 5.2 ), $3.4 \%$ (95\% CI 1 to 5.8 ) and $0.5 \%$ (95\% CI -0.7 to 1.7$)$ respectively. After adjusting for the effects of passive smoking, asthma in a parent, SES, preterm birth, neonatal intervention, child's age, sex, race, height and body mass index, birthweight was found to be associated with $\mathrm{FVC}$ and $\mathrm{FEV}_{1}$ but not with $\mathrm{FEV}_{1} / \mathrm{FVC}$ (Table 3). To better isolate the effect of birthweight from that of preterm birth, analysis was restricted to the 256 children born at term ( 37 weeks or more of gestation). The association between lung function and birthweight did not change appreciably. Among the 327 parents reporting whether their child was born preterm, 48 (14.7\%) of the children were born preterm. After adjusting for the effects of passive smoking, asthma in a parent, SES, birthweight, neonatal intervention, and child's age, sex, race, height and body mass index, preterm birth was associated with a reduction in $\mathrm{FEV}_{1} / \mathrm{FVC}$, but not with FVC or FEV1 (Table 3).

EIB and asthma: Exercise-induced bronchospasm by itself was not associated with birthweight. There was a tendency towards a higher risk of EIB with preterm birth, and this became significant when children with a history of asthma after adjusting for the child's age, sex, race, asthma in a parent, SES and birthweight were included (Table 3).

Airway responsiveness to methacholine: From the univariate analysis, the estimated change in the ranks of the dose response slope to methacholine for a $1 \mathrm{~kg}$ increase in birth- 


\begin{tabular}{|c|c|c|c|c|}
\hline & \multicolumn{4}{|c|}{ Exercise-induced bronchospasm or history of asthma } \\
\hline & \multicolumn{2}{|c|}{ Present } & \multicolumn{2}{|c|}{ Absent } \\
\hline & Participants $(n=187)$ & Nonparticipants $(\mathrm{n}=\mathbf{8 2})$ & Participants $(n=145)$ & Nonparticipants $(n=86)$ \\
\hline Caucasians (\%) & 74.6 & 86.1 & 82.0 & 83.3 \\
\hline Mothers smokes (\%) & 37.3 & 45.2 & 43.2 & 46.3 \\
\hline
\end{tabular}

TABLE 3

Relationship of birthweight and preterm birth to lung function, airway responsiveness and respiratory symptoms

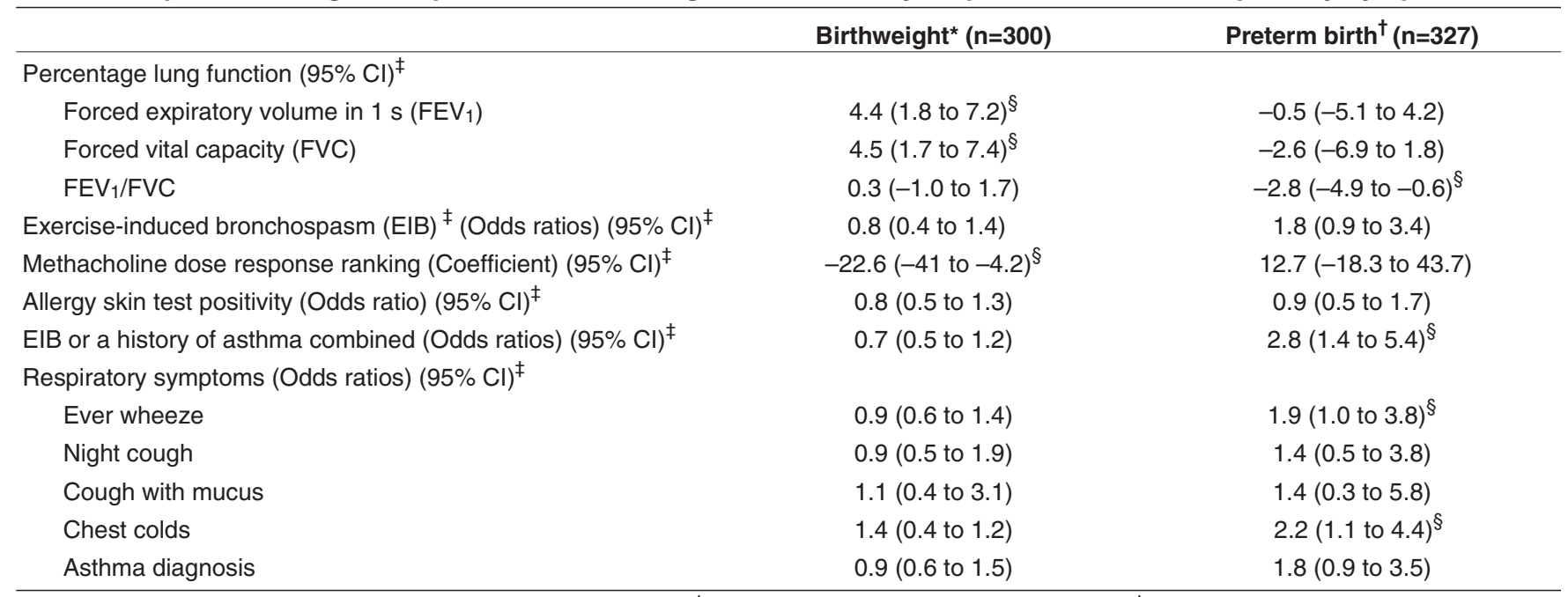

${ }^{*}$ Change in lung function is per kilogram increase in birthweight; ${ }^{\dagger}$ Child born before 37 weeks of gestation; ${ }^{\ddagger}$ See text for the standardizing variables; odds ratios are expressed per kilogram increase in birthweight and preterm birth (37 weeks or greater is the reference group); ${ }^{\S} P<0.05$

weight was -18.3 (95\% CI -36.5 to -0.04$)$. Thus, as birthweight increased, responsiveness to methacholine decreased. After adjusting for the effects of passive smoking, asthma in a parent, SES, age, sex and preterm birth, an increase in birthweight was still found to be associated with a decrease in the ranking for dose response slope to methacholine (Table 3). Further adjustment for airway calibre by including $\mathrm{FEV}_{1} / \mathrm{FVC}$ in the model did not significantly alter the association of birthweight to methacholine responsiveness; change in the ranking of DRS to methacholine per kg increase in birthweight was -22.3 (95\% CI -42.3 to -2.2$)$. On the other hand, preterm birth was not found to be associated with methacholine responsiveness (Table 3). The relationship between preterm birth and methacholine responsiveness was studied by treating methacholine responsiveness as positive (7.8 mmol methacholine or less causing a fall in $\mathrm{FEV}_{1}$ of $20 \%$ or more) or negative in a logistic regression model. After accounting for potential confounding variables, preterm birth was associated with increased risk of methacholine responsiveness but this did not achieve statistical significance (OR=1.89, 95\% CI 0.97 to 3.69).

Allergy skin test positivity: Birthweight and preterm birth were not found to be significantly related to positive allergy skin test, when examined not adjusted or after adjusting for the effects of the child's age, sex, race, asthma in a parent, SES and passive smoking (Table 3).

Respiratory symptoms: There was no statistically significant association between birthweight and any reported respiratory symptoms or a prior history of asthma considered alone. However, preterm birth was significantly related to ever wheeze and chest colds (Table 3).

\section{DISCUSSION}

In this cross-sectional study of school children, principally six to 12 years of age, we found increasing birthweight, but not preterm birth, to be associated with larger FVC, FEV 1 and decreasing airways responsiveness to methacholine (but not to exercise), while preterm birth, but not birthweight, was associated with a lower $\mathrm{FEV}_{1} / \mathrm{FVC}$, and a higher likelihood of ever wheeze, chest colds and EIB or a history of asthma combined, but not with airway responsiveness to either exercise or methacholine.

The overall response rate was quite low for an epidemiological study. Because nonparticipants were more likely to have mothers or fathers who smoke or mothers who had smoked during pregnancy, preterm children with asthma 
(or markers of asthma) may have been under-represented in our study sample. This selection bias should have resulted in an underestimation of their association in our study and could not, therefore, explain the positive findings of the study. Potential information bias stems from the fact that information on birthweight and the occurrence of preterm birth were obtained from the parents and depended upon accurate recall. Unfortunately, we were unable to validate the recalled birthweight and preterm birth information with the child's clinical records.

Several studies have examined the accuracy of parental recall of birthweight and gestational age (29). Maternal recall of birthweight was found to be highly accurate (within $10 \mathrm{~g}$ ) in $41 \%$ of cases, accurate to within $100 \mathrm{~g}$ in $75 \%$ and to within $200 \mathrm{~g}$ in $87 \%$. Accuracy of recall was not related to maternal age or education. Maternal recall of gestational age was found to be completely accurate in $39 \%$ of the cases, accurate to within one week in $74 \%$ and to within two weeks in $94 \%$ of the cases. More recently, Hakim et al (30) assessed agreement between maternal interview and medical recordbased gestational age by using data from a case-control study of childhood strabismus. Overall, $86 \%$ of mothers were within two weeks of the gestational age reported in the medical record. Parental reports of birthweight and gestational age, therefore, appear to be sufficiently accurate for epidemiological studies. Furthermore, lack of accuracy will result in attenuation of effects and, thus, would not explain our findings. The response to the question on preterm birth was 'yes/no' only, and this will have contributed to decreased precision. It is possible, therefore, that some of the effects on respiratory health which we are attributing to birthweight independently of preterm birth might actually be related to the latter; that is, inaccuracies in the assessment of preterm birth resulted in residual confounding of the association of lung health and birthweight.

Low birthweight was associated with increasing airway response to methacholine but not to EIB. The discrepancy in the results of the two airway challenges may be due to a greater sensitivity of methacholine for asthma (31) or differing mechanisms (32) and risk factors (33) for these markers of airway function. Although misclassification of the children by the exercise test is a possibility, care was taken to standardize the test (18). Thirty-nine children performed exercise tests on two different days, on average, 30 days apart. Agreement of the two tests as to the presence of EIB was $72 \%$. Furthermore, comparison of atmospheric conditions (eg, temperature and humidity in the room at testing) and indicators of effort (eg, per cent maximum heart rate) in those children with EIB and in those without EIB did not show important differences. Different boundaries defining significant exercise bronchospasm have been used in different studies, but a cut-off value of $10 \%$ or greater fall in $\mathrm{FEV}_{1}$ after exercise has been recommended most often (34).

In a recent report, Rona et al (5) also found birthweight to be an important determinant of FVC and FEV 1 . However, Chan et al (7) found birthweight predominantly affects airflow with little change in vital capacity. A number of possible explanations exist for the link between low birthweight and childhood respiratory health such as constitutional factors, preterm birth, an excess of lower respiratory infections in infancy, low social class or maternal smoking during pregnancy (15). In the present study, social class and maternal smoking did not appear to account for the link between birthweight and lung function. There was a significant adverse effect of preterm birth on airway calibre, consistent with the reports of others (8-10). Interestingly, the relationship between wheezing illness and preterm birth may be explained by the reduced airway calibre subsequent to preterm birth (35). The mechanisms by which birthweight and preterm birth affect respiratory health may differ. Hislop et al (36) demonstrated that between 22 weeks of gestation and eight months of age, the normal infant shows an age-related linear increase in airway diameter, with a proportional increase in the amount of smooth muscle, while the relative area occupied by submucosal glands decreases during this time. Preterm infants had normal-sized airways for their postconceptional age, but an increase in the total amount of bronchial smooth muscle and an increase in the number of goblet cells.

Most previous studies of the effect of birthweight and preterm birth on respiratory health have failed to differentiate these two factors, did not control for confounding factors and had limited power due to small sample sizes. The present study allowed for the evaluation of the independent effects of birthweight and preterm birth in a relatively large sample of children of whom information was obtained regarding potential confounding factors.

In conclusion, the present results provide evidence that birthweight is related to lung size and methacholine responsiveness while preterm birth appears to diminish airway size.

ACKNOWLEDGEMENTS: Research was supported by the Medical Research Council of Canada and the Respiratory Health Network of Centers of Excellence (Canada).

\section{REFERENCES}

1. Barker DJP, Godfrey KM, Fall C, Osmond C, Winter PD, Shaheen SO. Relation of birthweight and childhood respiratory infection to adult lung function and death from chronic obstructive airways disease. BMJ 1992;303:671-5.

2. Britten N, Davies JMC, Colley JRT. Early respiratory experience and subsequent cough and peak expiratory flow rate in 36 year old men and women. BMJ 1987;294:1317-20.

3. Martinez FD, Morgan WJ, Wright AL, Holberg CJ, Taussig LM. Diminished lung function as a predisposing factor for wheezing respiratory illness in infants. N Engl J Med 1988;319:1112-7.

4. Chan KN, Elliman A, Bryan E, Silverman M. Respiratory symptoms in children of low birthweight. Arch Dis Child 1989;64:1294-304.

5. Rona RJ, Gulliford MC, Chinn S. Effects of prematurity and intrauterine growth on respiratory health and lung function in childhood. BMJ 1993;306:817-20.

6. Seidman DS, Laor A, Gale R, Stevenson DK, Danon YL. Is low birthweight a risk factor for asthma during adolescence? Arch Dis Child 1991;66:584-7.

7. Chan KN, Noble-Jamieson CM, Elliman A, Bryan EM, Silverman M. Lung function in children of low birthweight. Arch Dis Child 1989;64:1284-93.

8. Chan KN, Wong YC, Silverman M. Relationship between infant lung mechanics and childhood lung function in children of very low birthweight. Pediatr Pulmonol 1990;8:74-81. 
9. Coates AL, Bergsteinsson H, Desmond K, Outerbridge EW, Beaudry PH. Long-term pulmonary sequelae of premature birth with and without idiopathic respiratory distress syndrome. J Pediatr 1977;990:611-6

10. Mansell AL, Driscoll JM, James LS. Pulmonary follow up of moderately low birthweight infants with and without respiratory distress syndrome. J Pediatr 1987;110:111-5.

11. Von Mutius E, Nicolai T, Martinez FD. Prematurity as a risk factor for asthma in preadolescent children. J Pediatr 1993;123:223-9.

12. Galdes-Sebaldt M, Sheller JR, Grogaard J, Stahlman M. Prematurity is associated with abnormal airway function in childhood. Pediatr Pulmonol 1989;7:259-64.

13. Lucas A, Brooke OG, Cole TJ, Morley R, Bamford MF. Food and drug reactions, wheezing, and eczema in pre-term infants. Arch Dis Child 1990;65:411-5.

14. Stein A, Campbell EA, Day A, McPherson K, Cooper PJ. Social adversity, low birthweight, and per term delivery. BMJ (Clin Res Ed) 1987;295:291-3.

15. Colley JRT, Douglas JWB, Reid DD. Respiratory disease in young adults: influence of early childhood lower respiratory tract illness, social class, air pollution, and smoking. BMJ 1973;iii:195-8.

16. American Thoracic Society. Standardization of spirometry - 1987 update. Am Rev Respir Dis 1987;136:1285-98.

17. Kanner RE, Schenker MB, Munoz A, Speizer FE. Spirometry in children. Methodology for obtaining optimal results for clinical and epidemiologic studies. Am Rev Respir Dis 1983;127:720-4.

18. Tsanakas JN, Milner RDG, Bannister OM, Boon WA. Free running asthma screening test. Arch Dis Child 1988;63:261-5.

19. Ferris BG. Epidemiology Standardization Project (American Thoracic Society). Am Rev Respir Dis 1978;118:1-120.

20. Statistics Canada. Standard Occupational Classification (1980) (Catalogue 12-565E). Ottawa: Statistics Canada, 1980.

21. Blishen BR, Carroll WK, Moore C. The 1981 socioeconomic index for occupations in Canada. Can Rev Soc Anth 1987;24:465-88.

22. Yan K, Salome C, Woolcock AJ. Rapid method for measurement of bronchial responsiveness. Thorax 1983;38:760-5.

23. Dreborg S, Holgersson M, Nilsson G, Zetterstrom O. Dose response relationship of allergen, histamine and histamine releasers in skin prick test and precision of the skin prick test method. Allergy 1987:42:117-25.

24. Peat JK, Woolcock AJ. Sensitivity to common allergens: Relation to respiratory symptoms and bronchial hyper-responsiveness in children from three different climatic areas of Australia. Clin Exp Allergy 1991;21:573-81.

25. Kleinbaum DG, Kupper LL, Morgenstern H. Epidemiologic Research: Principles and Quantitative Methods. Belmont: Lifetime Learning, 1982:419-46.

26. O'Connor G, Sparrow D, Taylor D, Segal M, Weiss S, Eleuteri D. Analysis of dose-response curves to methacholine. An approach suitable for population studies. Am Rev Respir Dis 1987;136:1423-7.

27. Ware JH, Dockery DW, Spiro A III, Speizer FE, Ferris BG Jr. Passive smoking, gas cooking, and respiratory health of children living in six cities. Am Rev Respir Dis 1984;129:366-74.

28. Osterman JW, Armstrong BG, Ledoux E, Sloan M, Ernst P. Comparison of French and English versions of the American Thoracic Society Respiratory Questionnaire in a bilingual working population. Int J Epidemiol 1991;20:138-43.

29. Seidman DS, Slater PE, Ever-Hadani P, Gale R. Accuracy of mothers' recall of birthweight and gestational age. Br J Obstet Gynaecol 1987;94:731-5.

30. Hakim RB, Tielsch JM, See LC. Agreement between maternal interview and medical record-based gestational age. Am J Epidemiol 1992;136:566-73.

31. Pattemore PK, Asher MI, Harrison AC, Mitchell EA, Rea HH, Stewart AW. The interrelationship among bronchial hyperresponsiveness, the diagnosis of asthma and asthma symptoms. Am Rev Respir Dis 1990;142:549-54.

32. Bhagat RG, Grunstein MM. Comparison of responsiveness to methacholine, histamine, and exercise in sub-groups of asthmatic children. Am Rev Respir Dis 1984;129:221-4.

33. Clough JB, Hutchinson SA, Williams JD, Holgate ST. Airway response to exercise and methacholine in children with respiratory symptoms. Arch Dis Child 1991;16:579-83.

34. Eggleston PA, Rosenthal RR, Anderson SA, et al. Guidelines for the methodology of exercise challenge testing of asthmatics. J Allergy Clin Immunol 1979;64:642-5.

35. Tager IB, Hanrahan JP, Tosteson TD, et al. Lung function, pre- and post-natal smoke exposure, and wheezing in the first year of life. Am Rev Respir Dis 1993;147:811-7.

36. Hislop A, Wigglesworth JS, Desai R, Aber V. The effects of preterm delivery and mechanical ventilation on human lung growth. Early Human Dev 1987;15:147-64. 


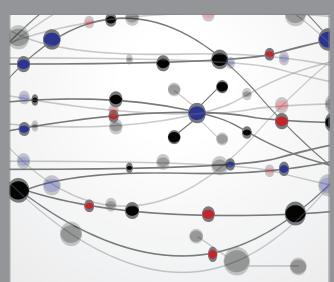

The Scientific World Journal
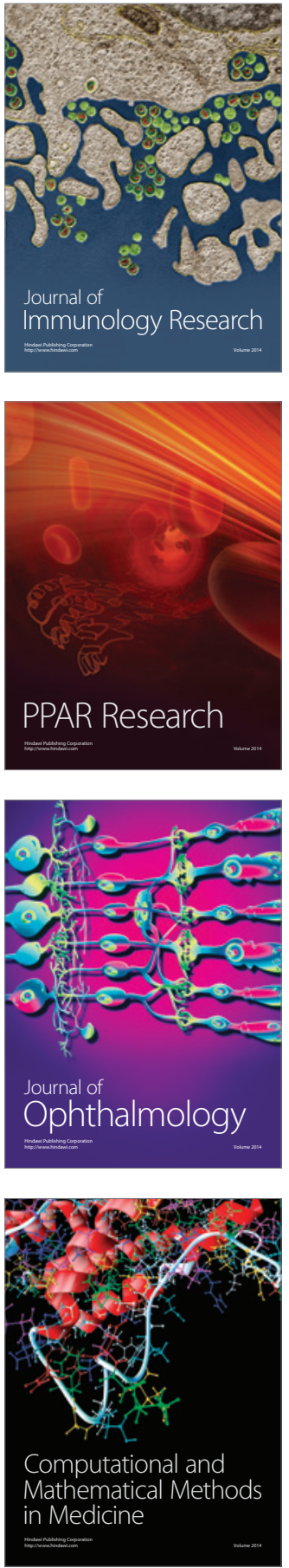

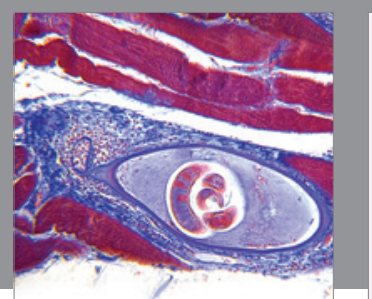

Gastroenterology Research and Practice

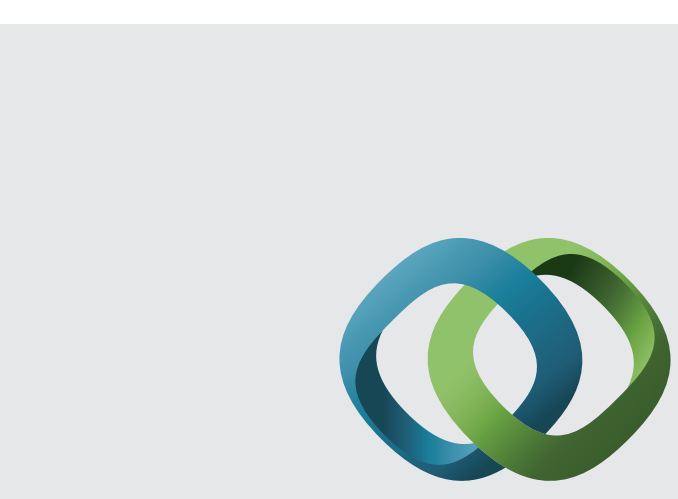

\section{Hindawi}

Submit your manuscripts at

http://www.hindawi.com
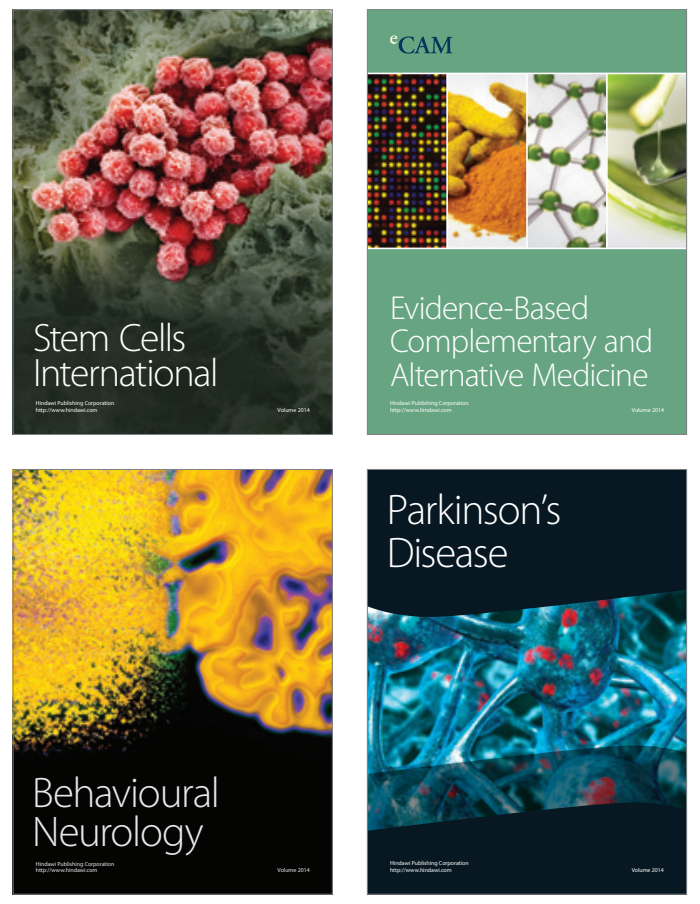
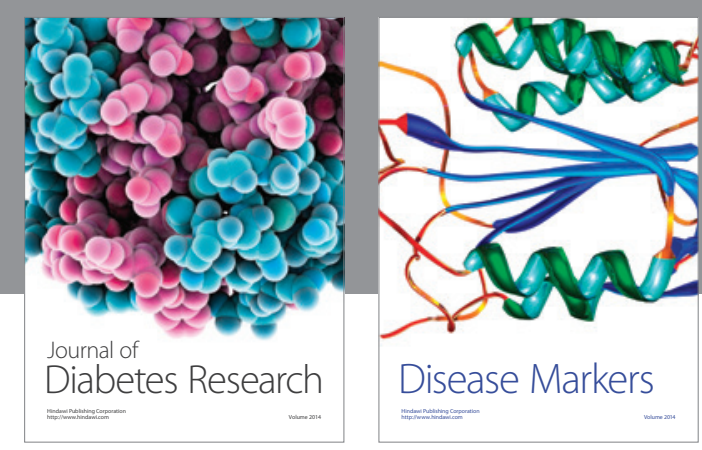

Disease Markers
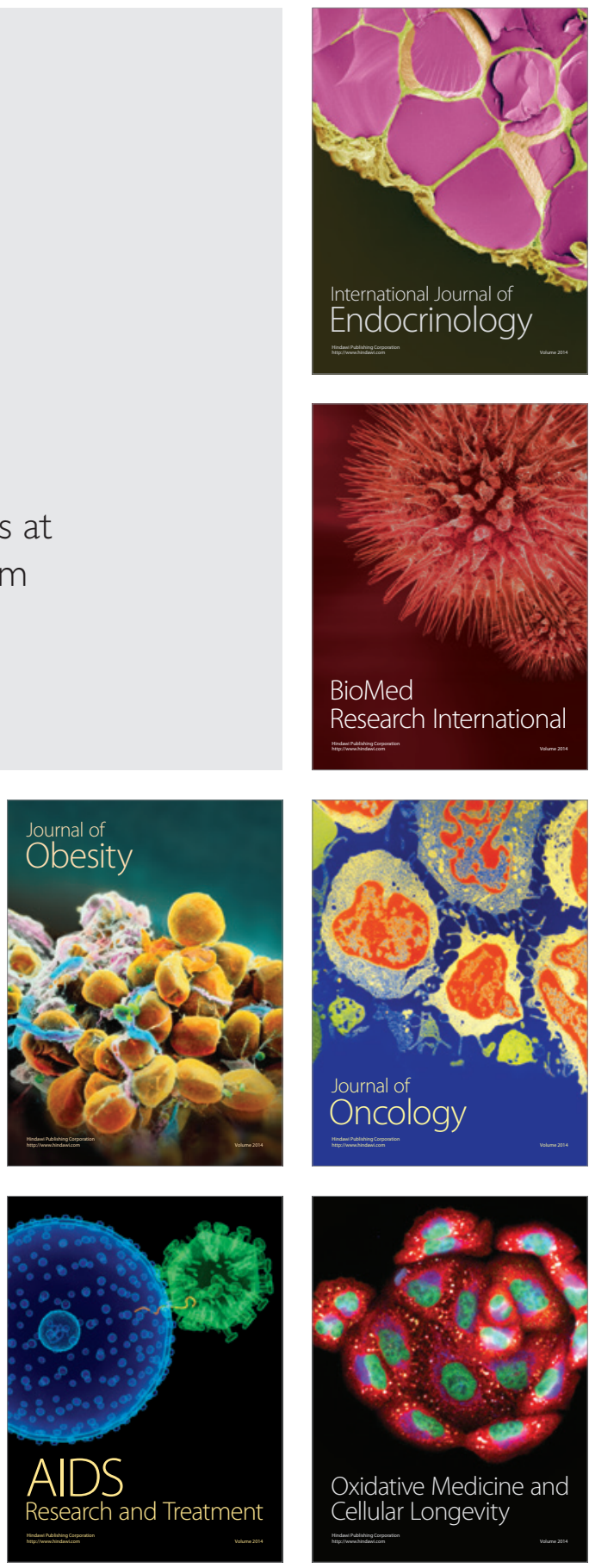